Yue Sun*, Tianyu Yang and Wenxiang Wang

\title{
The crystal structure of $N^{6}, N^{6^{\prime}}$-di(pyridin-2-yl)- [2,2'-bipyridine]-6,6'-diamine, $\mathrm{C}_{20} \mathrm{H}_{16} \mathrm{~N}_{6}$
}

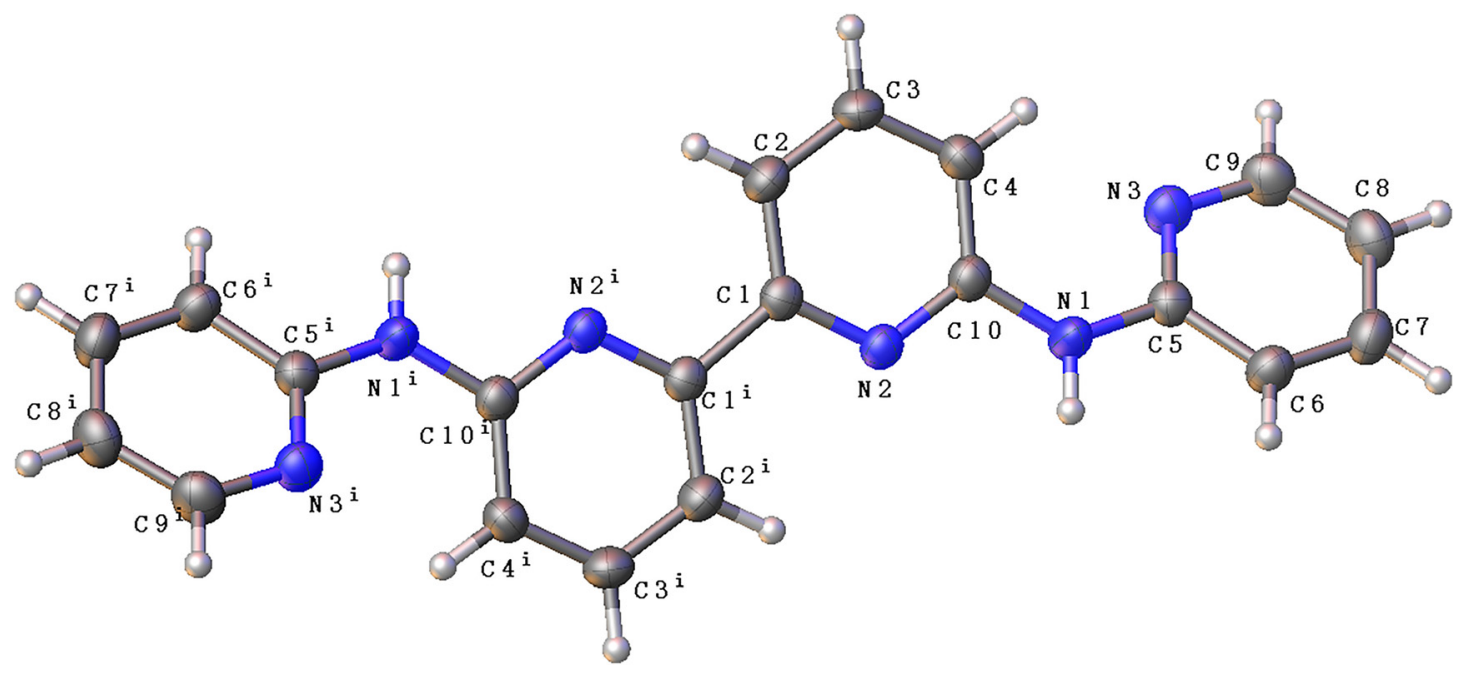

https://doi.org/10.1515/ncrs-2021-0373

Received September 28, 2021; accepted October 22, 2021; published online November 8, 2021

\begin{abstract}
$\mathrm{C}_{20} \mathrm{H}_{16} \mathrm{~N}_{6}$, monoclinic, $P 2_{1} / c$ (no. 14), $a=7.6623(4) \AA$, $b=11.8206(5) \AA ⿻ \quad c=8.8960(4) \AA, \quad \beta=91.825(2)^{\circ}$, $V=805.33(7) \AA^{3}, Z=2, R_{g t}(F)=0.0577, w R_{\text {ref }}\left(F^{2}\right)=0.1588$, $\mathrm{T}=200(2) \mathrm{K}$.
\end{abstract}

\section{CCDC no.: 2108951}

Table 1 contains crystallographic data and Table 2 contains the list of the atoms including atomic coordinates and displacement parameters.

\section{Source of materials}

About $2.0 \mathrm{mmol}$ 6,6'-diamino-2,2'-bipyridine, $6.0 \mathrm{mmol}$ 2-bromopyridine and $8.1 \mathrm{mmol} \mathrm{KO}^{t} \mathrm{Bu}$ were weighed in a

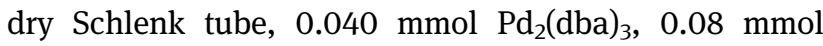

\footnotetext{
*Corresponding author: Yue Sun, Jiangsu Vocational Institute of Architectural Technology, Xuzhou 221116, P. R. China,

E-mail: sunyue3721@163.com

Tianyu Yang and Wenxiang Wang, Jiangsu Vocational Institute of Architectural Technology, Xuzhou 221116, P. R. China. https:// orcid.org/0000-0001-7297-3387 (W. Wang)
}

Table 1: Data collection and handling.

\begin{tabular}{ll}
\hline Crystal: & Prism, colorless \\
Size: & $0.35 \times 0.18 \times 0.16 \mathrm{~mm}$ \\
Wavelength: & Mo $K \alpha$ radiation $(0.71073 \AA$ A $)$ \\
$\mu:$ & $0.09 \mathrm{~mm}^{-1}$ \\
Diffractometer, scan mode: & $\mathrm{SCXmini}, \omega$-scans \\
$\theta_{\text {max }}$, completeness: & $27.5^{\circ},>99 \%$ \\
$N(h k l)_{\text {measured }}, N(h k l)_{\text {unique }}, R_{\text {int }}:$ & $11,399,1848,0.042$ \\
Criterion for $I_{\text {obs }}, N(h k l)_{\text {gt: }}$ & $I_{\text {obs }}>2 \sigma\left(I_{\text {obs }}\right), 1504$ \\
$N(\text { param })_{\text {refined }}:$ & 119 \\
Programs: & CrystalClear [1], OLEX2 [2], \\
& SHELX [3, 4] \\
\hline
\end{tabular}

BINAP as catalyst and $30 \mathrm{~mL}$ of dry, degassed toluene as solvent were added. The mixture was heated to $80^{\circ} \mathrm{C}$ and stirred under argon for three days before it was cooled to room temperature. After that $150 \mathrm{~mL}$ water were added and stirred vigorously for $1 \mathrm{~h}$. The solid was filtered out and the title product was obtained by recrystallization from a hot mixture of methanol and DMF.

\section{Experimental details}

Hydrogen atoms were placed in their geometrically idealized positions and constrained to ride on their parent atoms. 
Table 2: Fractional atomic coordinates and isotropic or equivalent isotropic displacement parameters $\left(\AA^{2}\right)$.

\begin{tabular}{lrrrr}
\hline Atom & $\boldsymbol{x}$ & $\boldsymbol{y}$ & $\boldsymbol{z}$ & \multicolumn{1}{c}{$\boldsymbol{U}_{\text {iso }} / \boldsymbol{U}_{\text {eq }}$} \\
\hline N2 & $0.17893(18)$ & $0.90166(11)$ & $0.49443(14)$ & $0.0247(4)$ \\
N1 & $0.3891(2)$ & $0.76545(13)$ & $0.49976(16)$ & $0.0316(4)$ \\
H1 & 0.422127 & 0.799670 & 0.417555 & $0.038^{*}$ \\
N3 & $0.4950(2)$ & $0.64946(12)$ & $0.69759(16)$ & $0.0303(4)$ \\
C1 & $0.0235(2)$ & $0.94368(13)$ & $0.53295(17)$ & $0.0234(4)$ \\
C10 & $0.2317(2)$ & $0.80296(14)$ & $0.55461(17)$ & $0.0253(4)$ \\
C4 & $0.1321(2)$ & $0.74258(14)$ & $0.65720(19)$ & $0.0291(4)$ \\
H4 & 0.173922 & 0.674092 & 0.701095 & $0.035^{*}$ \\
C2 & $-0.0862(2)$ & $0.88787(15)$ & $0.62940(19)$ & $0.0293(4)$ \\
H2 & -0.197151 & 0.918115 & 0.652035 & $0.035^{*}$ \\
C5 & $0.5019(2)$ & $0.68280(14)$ & $0.55401(18)$ & $0.0265(4)$ \\
C3 & $-0.0283(2)$ & $0.78606(15)$ & $0.6920(2)$ & $0.0314(4)$ \\
H3 & -0.100128 & 0.746299 & 0.759236 & $0.038^{*}$ \\
C6 & $0.6245(2)$ & $0.63903(15)$ & $0.4550(2)$ & $0.0311(4)$ \\
H6 & 0.628163 & 0.665418 & 0.354263 & $0.037^{*}$ \\
C7 & $0.7385(3)$ & $0.55759(16)$ & $0.5067(2)$ & $0.0346(5)$ \\
H7 & 0.822917 & 0.526926 & 0.442220 & $0.042^{*}$ \\
C8 & $0.7297(3)$ & $0.52024(16)$ & $0.6542(2)$ & $0.0356(5)$ \\
H8 & 0.806287 & 0.463001 & 0.691977 & $0.043^{*}$ \\
C9 & $0.6076(3)$ & $0.56813(16)$ & $0.7439(2)$ & $0.0348(5)$ \\
H9 & 0.602091 & 0.542426 & 0.844852 & $0.042^{*}$ \\
\hline & & & &
\end{tabular}

\section{Comment}

The title compound is an useful organic blocks for the synthesis of metal organic hybrid phase transition materials [5-7], which are used in nonvolatile memory storage [8], electronics [9], optics [10] and telecom shelters [11]. It is also an interesting work to try to detect metal ion pollutants using this compound [12]. In our exploration on multiferroic compounds and searching for new metal organic hybrid phase transition materials [13], we come across the crystal structure of the title compound. In the title molecule, all bond lengths are in normal ranges [14-16]. The molecular structure is centro-symmetric arranged around a inversion center (see the Figure). The dihedral angle between the pyridine rings of each half molecular is $33.8^{\circ}$. In the crystal, $\mathrm{N}-\mathrm{H} \cdots \mathrm{N}$ hydrogen bonds stabilized the structure.

Author contributions: All the authors have accepted responsibility for the entire content of this submitted manuscript and approved submission.

Research funding: This work was supported by 'Innovative Practice Project of Jiangsu Vocational Institute of Architectural Technology (JYSCZ19-13)' and 'Key Research and Development Program of Xuzhou (KC18134)'.

Conflict of interest statement: The authors declare no conflicts of interest regarding this article.

\section{References}

1. Rigaku. CrystalClearSM Expert; Rigaku Corporation: Tokyo, Japan, 2005.

2. Bourhis L. J., Dolomanov O. V., Gildea R. J., Howard J. A. K., Puschmann $\mathrm{H}$. The anatomy of a comprehensive constrained, restrained refinement program for the modern computing environment-olex2 dissected. Acta Crystallogr. 2015, A71, 59-75.

3. Sheldrick G. M. SHELXT - integrated space-group and crystal structure determination. Acta Crystallogr. 2015, A71, 3-8.

4. Sheldrick G. M. Crystal structure refinement with SHELXL. Acta Crystallogr. 2015, C71, 3-8.

5. Bonnet S. G. M., Costa J. S., Siegler M. A., Spek A. L., Bousseksou A., Fu W. T., Gamez P., Reedijk J. Influence of sample preparation, temperature, light, and pressure on the two-step spin crossover mononuclear compound [Fe(bapbpy)(NCS) ${ }_{2}$ ]. Chem. Mater. 2009, 21, 1123-1136.

6. Vincent H. S., Anja B., Mathijs F. W., Samantha L. H., Bianka S., Corjan van de G., Maxime A. S., Tiziano M., Francesco P., Marta F., Paola G., Carla B., Luigi M., Sylvestre B. Induction of a four-way junction structure in the DNA palindromic hexanucleotide 5'-d(CGTACG)-3' by a mononuclear platinum complex. Angew. Chem. Int. Ed. 2019, 58, 9378-9382.

7. Nicolas Q., Sun D. Y., Jennifer F., Jacques P., Martin J. F., Murielle C. K., Vincent A. Electrocatalytic hydrogen evolution with a cobalt complex bearing pendant proton relays: acid strength and applied potential govern mechanism and stability. J. Am. Chem. Soc. 2020, 142, 274-282.

8. Gamba I., Mutikainen I., Bouwman E., Reedijk J., Bonnet S. Synthesis and characterization of copper complexes of a tetrapyridyl ligand, and their use in the catalytic aerobic oxidation of benzyl alcohol. Eur. J. Inorg. Chem. 2013, 1, 115-123.

9. Bonnet S., Siegler M. A., Costa J. S., Molnar G., Bousseksou A., Spek A. L., Gamez P., Reedijk J. A two-step spin crossover mononuclear iron(ii) complex with a [HS-LS-LS] intermediate phase. Chem. Commun. 2008, 5619-5621; https://doi.org/10. 1039/b811746b.

10. Queyriaux N., Abel K., Fize J., Pécaut J., Orio M., Hammarström L. From non-innocent to guilty: on the role of redox-active ligands in the electro-assisted reduction of $\mathrm{CO}_{2}$ mediated by a cobalt(II)polypyridyl complex. Sustain. Energy Fuel. 2020, 4, 3668-3676.

11. Vincent H. S., Geri F. M., Maxime A. S., Luigi M., Sylvestre B. Controlling with light the interaction between trans-tetrapyridyl ruthenium complexes and an oligonucleotide. Dalton Trans. 2018, 47, 507-516.

12. Molenbroek E., Straathof N., Duck S., Rashid Z., Lenthe J. H., LutZ M., Gandubert A., Gebbink R. J. M. K., Cola L. D., Bonnet S. Zinc coordination to the bapby ligand in homogeneous solutions and at liposomes: zinc detection via fluorescence enhancement. Dalton Trans. 2013, 42, 2973-2984.

13. Wang W. X., Cai H. L., Xiong R. G. Hydrothermal synthesis method of 5-(4'-methylbiphenyl-2-yl)-1H-tetrazole. Chin. Chem. Lett. 2013, 24, 783-785.

14. Queyriaux N., Giannoudis E., Windle C. D., Roy S., Pécaut J., Coutsolelos A. G., Artero V., Chavarot-Kerlidou M. A noble metalfree photocatalytic system based on a novel cobalt tetrapyridyl catalyst for hydrogen production in fully aqueous medium. Sustain. Energy Fuel. 2018, 2, 553-557. 
15. Zheng S., Siegler M. A., Sanchez J. C., Fu W. T., Bonnet S. Effect of metal dilution on the thermal spin transition of

$\left.\left[\mathrm{Fe}_{x} \mathrm{Zn}_{1-x} \text { (bapbpy)(NCS)}\right)_{2}\right]$. Eur. J. Inorg. Chem. 2013, 5, 1033-1042.
16. Wang W.X. The crystal structure of ethyl 5-methyl-7-(4-(phenylthio) phenyl)-4,7-dihydrotetrazolo[1,5-a]pyrimidine-6-carboxylate, $\mathrm{C}_{20} \mathrm{H}_{19} \mathrm{~N}_{5} \mathrm{O}_{2}$ S. Z. Kristallogr. N. Cryst. Struct. 2021, 236, 781-783. 